\title{
Article \\ The Content of Polyarenes in Soils of Antarctica: Variability across Landscapes
}

\author{
Evgeny Lodygin ${ }^{1}\left(\mathbb{D}\right.$, Evgeny Abakumov ${ }^{2, *(\mathbb{D})}$ and Timur Nizamutdinov ${ }^{2}(\mathbb{D}$ \\ 1 Komi Science Center, Institute of Biology, Ural Branch, Russian Academy of Sciences, \\ 167982 Syktyvkar, Russia; lodigin@ib.komisc.ru \\ 2 Department of Applied Ecology, Saint Petersburg State University, 199178 St. Petersburg, Russia; \\ timur_nizam@mail.ru \\ * Correspondence: e_abakumov@mail.ru or e.abakumov@spbu.ru
}

Citation: Lodygin, E.; Abakumov, E.; Nizamutdinov, T. The Content of Polyarenes in Soils of Antarctica: Variability across Landscapes. Land 2021, 10, 1162. https://doi.org/ $10.3390 /$ land 10111162

Academic Editors: Wojciech Zgłobicki and Cezary Kabala

Received: 25 August 2021

Accepted: 27 October 2021

Published: 30 October 2021

Publisher's Note: MDPI stays neutral with regard to jurisdictional claims in published maps and institutional affiliations.

Copyright: (c) 2021 by the authors. Licensee MDPI, Basel, Switzerland. This article is an open access article distributed under the terms and conditions of the Creative Commons Attribution (CC BY) license (https:/ / creativecommons.org/licenses/by/ $4.0 /)$.

\begin{abstract}
Soil cover of the Earth is faced with intensive polychemical contamination. The pathways of the key pollutants are not investigated enough. Thus, the occasional transportation of soils to remote regions could serve as an informative tool for the elaboration of threshold levels of hazardous materials concentration. One of the most striking examples of such transboundary impact was the transfer of soils and grounds to the Antarctic stations Russkaya and Leningradskaya (before the implementation of the Madrid Protocol in 1991). Thus, the complex investigation of qualitative and quantitative composition of polycyclic aromatic hydrocarbons (PAHs) in soils of various genesis (transported from Eurasia and pristine) of Antarctic have been conducted by the method of high-performance liquid chromatography (HPLC) in a gradient elution mode. The variability of PAHs content was evaluated across landscapes: pristine (the Hudson Mountains and the Haswell Archipelago), contaminated soils (stations Myrniy, Druzhnaya 4 and Bellinshausen) and unique samples of former agrosoils transported by fly in-fly of polar staff from St. Petersburg to Antarctic for local polar greenhouses in the Soviet times, when it was not strictly prohibited. The selected objects of study allow us to not only estimate the degree of contamination of Antarctic soils and grounds, but to also make it possible to assess the rate of PAH degradation in Antarctic conditions. Both high molecular and low molecular PAHs are accumulated following intense anthropogenic activity (fossil organic fuel combustion). The PAHs pool is dominated by low molecular weight representatives (naphthalene, phenanthrene, fluoranthene, pyrene). In most cases, the highest concentrations of benz(a)pyrene does not exceed the Russian Threshold Standard rate, which is the strictest one in the world. The statistical analysis of raw data allowed us to conclude that the contamination of pristine soils of Antarctica across variable landscapes is at the very initial stage. However, we recorded extremely high levels of PAHs in the transported former agrosoils. We can assume that our data could be used as background levels for the elaboration of threshold concentrations of the PAHs for such an internationally managed region as Antarctica.
\end{abstract}

Keywords: polycyclic aromatic hydrocarbons; soil; Antarctica; PAH isomer ratios

\section{Introduction}

Antarctica is a continent located remotely from industrial regions and, therefore, relatively mildly affected by anthropogenic impact. However, even Antarctica can no longer be considered a clean continent, which is explained by both direct and indirect anthropogenic pollution. Human presence in Antarctica, such as operating scientific stations, tourist facilities, etc., leads to air pollution, fuel spills, waste and wastewater discharge into the environment [1]. At present, the Madrid Protocol prohibits the importation into the territory of Antarctica of various biological substrates and soils [2], but in Soviet times there were facts of transporting soils and grounds from St. Petersburg on the territory of the Leningradskaya and Russkaya Stations. At that time, it was not strictly forbidden 
and sometimes such phenomena did happen. Moreover, no control was carried out on the level of contamination of these former agrosoils, which resulted in the transfer to the Antarctic continent of non-typical pollutants for this region. Our study is novel in many aspects because it is not only associated with the evaluation of current ecotoxicological states of the soils, located in the vicinities of the Antarctic stations and soils of mature ecosystems, but also because we aimed to obtain information about the fact of agrosoils transportation and we have possibilities to estimate the degree of the PAHs stabilization rate in severe polar conditions with limited microbiological activity. The fact of soil and grounds transportation which had appeared more than 40 years ago and the existence of these grounds in conservated stations represents quite an interesting model for model ecotoxicological research.

In addition, persistent organic pollutants, including polycyclic aromatic hydrocarbons (PAHs), are transported over long distances in the atmosphere from industrialized regions of the southern hemisphere [3-6]. PAHs are compounds composed of several condensed benzene rings with benzo[a]pyrene as the lead component. These are divided into "light" PAHs with two to four and "heavy" PAHs with five to six aromatic rings. PAHs are harmful to health and are classified as genotoxic carcinogens. The European Food Safety Authority (EFSA) considers 16 PAHs compounds classified as toxicologically relevant to humans because of their food intake. Due to their physicochemical properties, ecotoxicants pass up the polar food chains rich in fats and are accumulated in biota. The combination of harsh climatic conditions with physical and chemical properties of persistent toxic compounds converts polar regions into an area of final accumulation of these substances, which can lead to their increased content as compared to the source regions [7]. The human presence in this region has become possible due to the widespread use of fossil (caustobiolith) fuels for supply vessels, tourist, research, and other land vehicles, as well as for heating and lighting research stations [8]. These days, most Antarctic research stations are located in coastal areas, where they discharge untreated sewage and dispose of household waste immediately into the ocean $[9,10]$. Burning fossil fuels can be considered one of the most important anthropogenic sources in terms of environmental pollution with substances such as PAHs. Therefore, monitoring this group of compounds can be used to determine the anthropogenic load in Antarctica. While the Protocol on Environmental Protection to the Antarctic Treaty (Madrid Protocol, 1991) provides strict guidelines for the protection of the Antarctic environment and sets forth obligations to minimize any human activity on the continent and in the South Sea, global warming, growing population and industrial development in the Southern Hemisphere. in addition to the logistical development of the continent, are likely to increase the exposure of the Antarctic ecosystems to anthropogenic pollution.

Polycyclic aromatic hydrocarbons are common organic pollutants that exhibit carcinogenic, mutagenic and toxic effects on living organisms, and are included in the list of priorities for continuous monitoring, for which appropriate analytical methods have been developed [11-18]. PAHs are mainly formed from anthropogenic sources, including through the combustion of fossil fuels, vehicle emissions, and spills of oil and petroleum by-products $[19,20]$. Given the variety of processes leading to PAH formation, it is thermal action on organic matter that should be considered as the most common mechanism for PAH generation [21,22]. Higher molecular weight PAHs are less susceptible to microbial degradation than lower molecular weight PAHs, especially in polar regions with low temperatures [23,24]. Thus, PAHs are deposited and preserved in soils and bottom sediments and serve as suitable objects for studying anthropogenic organic matter entering soils.

In connection with the above-mentioned, this work aims at a primary study of the content and composition of PAHs in the former agrosoils, transported to Antarctica from Eurasia in comparison with soils of various polar Antarctic stations. The working hypothesis was that transported soils bring high rates of PAHs accumulated in urbanized environments of the Russian North-West and the levels of soil contaminations stay stable due to the absence or very low microbiological decomposing rate in the severe climatic con- 
ditions of Antarctica. The determination of trends and causes of anthropogenic pollution of Antarctic soils and assessment of the levels of PAHs accumulation in them is also quite interesting because the environmental rationing and management in Antarctica requires the elaboration of threshold levels for soils of this remote region.

\section{Materials and Methods}

The environmental and physiographic characteristics of the soils are given in the reference sources [23]. Soil samples from various regions of Antarctica were studied: the sub-Antarctic zone, coastal and continental Antarctica. The soil of the Hudson Mountains (Mount Moses and Maish Nunatak), the Pacific sector of West Antarctica (with no anthropogenic impact), and slightly altered landscapes of the Haswell Archipelago ( $66^{\circ} 31^{\prime} 34^{\prime \prime} \mathrm{S}$, $92^{\circ} 59^{\prime} 55^{\prime \prime}$ E) were taken as a reference sample. Soils exposed to heavy anthropogenic impact-at the airfield at Bellingshausen Station $\left(62^{\circ} 12^{\prime} 28^{\prime \prime} \mathrm{S}, 58^{\circ} 54^{\prime} 14^{\prime \prime} \mathrm{W}\right)$, at the open-air storage area for petroleum products at Druzhnaya 4 Station $\left(69^{\circ} 44^{\prime} 46^{\prime \prime} \mathrm{S}, 73^{\circ} 42^{\prime} 10^{\prime \prime} \mathrm{E}\right)$ were chosen to determine pollution trends in natural soils in intensely developed areas. To analyze the pollution resistance, a soil sample in the vicinity of Leningradskaya Station was examined. The samples were taken in January 2008 immediately after the station had been deactivated after a 20-year period of abandonment. The soils are represented by underdeveloped varieties (mostly Leptosols, without visible morphological signs of pollution). The data on the soils were published in earlier studies [25-27].

Imported former agrosoils for planting flowers and vegetables in small greenhouses were chosen to act as contrasting objects at the Russkaya and Leningradskaya Stations. It should be noted that these imported soils have been kept at the stations for more than 20 years after their emergency conservation. These unique samples, which stayed abundantly on the territory of the Russkaya and Leningradskaya stations could be considered as good model samples for the evaluation of the stability of soil contamination levels during the 20 years in the severe climatic conditions of remote Antarctic landscapes.

Samples were taken during the 53rd and 55th Russian Antarctic expeditions by E.V. Abakumov, after which they were processed (labeling, recording) in the vesel's laboratory and delivered by sea in a chilled state to St. Petersburg State University. The localization of the study items is shown in Figure 1. The photos of the soils and anthropogenic sites can be seen in Figure 2.

The determination of PAHs in soils is based on a number of methods [14,28] and works $[29,30]$. Extraction was carried out at room temperature with a hexane/acetone mixture $(1 / 1)$ with ultrasonic treatment of the extraction system on an ultrasonic cleaner Branson 5510 (USA) following the procedure [12]. The PAH fraction was purified by silica gel column chromatography following the purification procedure [13].

Qualitative and quantitative PAHs content in soils was determined by means of reversed-phase HPLC in a gradient mode and spectrofluorimetric detection on a Lumakhrom chromatograph (Lumex, Russia). Chromatography was performed at $30^{\circ} \mathrm{C}$ on a Supelco Supelcosil ${ }^{\mathrm{TM}}$ LC-PAH 5- $\mu \mathrm{m}$ column $(25 \mathrm{~cm} \times 2.1 \mathrm{~mm})$. An acetonitrile/water gradient was used as the mobile phase. A $10-\mu \mathrm{L}$ sample was injected with a sampling valve. PAHs were identified through retention times and comparison of the fluorescence spectra of the components leaving the column to the spectra of standard PAHs. The quantitative analysis of PAHs was carried out with the external standard method. To assess the accuracy of the method, a PAH-containing sediment standard (Standard Reference Material ${ }^{\circledR} 1944$ New York/New Jersey Waterway Sediment (National Institute of Standards and Technology NIST, Gaithersburg, MD, USA)) was exposed to the analysis above, which showed satisfactory results. The results were processed by means of the SIGMAPLOT 6 software. 


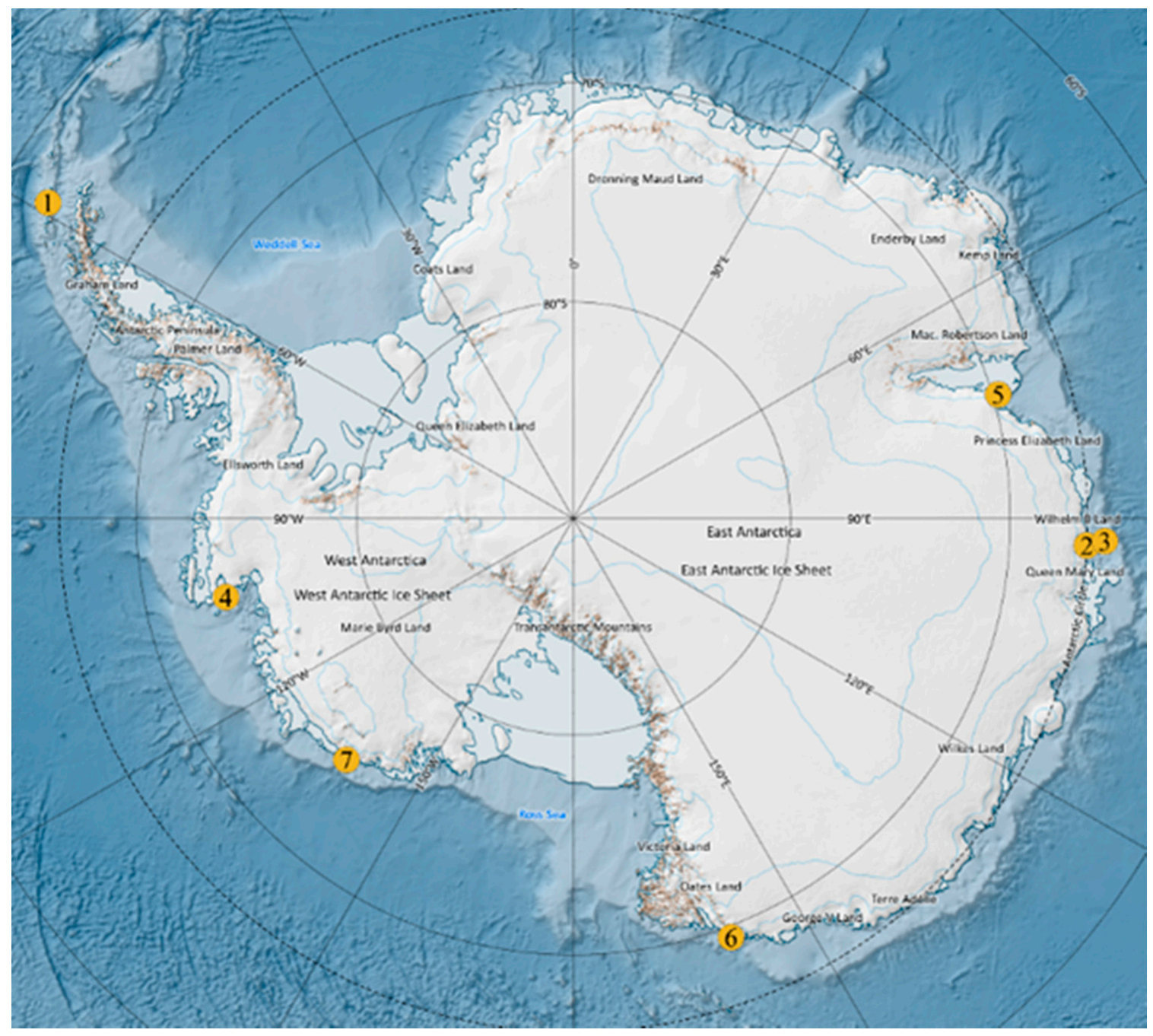

Figure 1. Localization of soil sampling sites in Antarctica: 1-Bellingshausen Station, King George Island, 2-Mirniy Station, 3-the Haswell Archipelago, 4-the Hudson Mountains, 5-Druzhnaya 4 Station, 6-Leningradskaya Station and 7-Russkaya Station.

The possible genesis of PAHs was identified with the help of diagnostic isomeric ratios of individual PAHs concentrations: PHEN/ANTH; ANTH/(ANT+PHEN); BaANTH/ (BaANTH+CHRY); BaPYR/BghiPER. The PHEN/ANTH ratio exceeding 10 indicates the petrogenic origin of these polyarenes, while the one lower than 10 is pyrogenic. [31]. Values of the ANTH/(ANTH+PHEN) ratio lower than 0.1 indicate the petrogenic origin of $\mathrm{PAH}$, a value of over 0.1 points out pyrogenic sources [32]. The diagnostic ratio $\mathrm{BaANTH} /(\mathrm{BaANTH}+\mathrm{CHRY})$ below 0.2 is indicative of background (petrogenic) origin of hydrocarbons, $0.20-0.35-$ of mixed origin, above 0.35 is an indicator of the pyrogenic origin of PAHs [33]. The ratio of heavy PAHs BaPYR/BghiPER of less than 0.6 indicates a nonvehicle origin of polyarenes, while more than 0.6 is an indicator of the PAHs originating from transport sources [34]. 


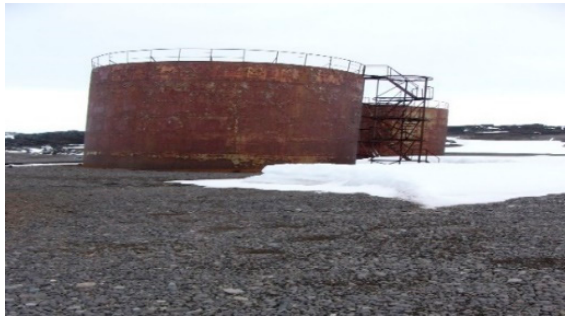

(a)
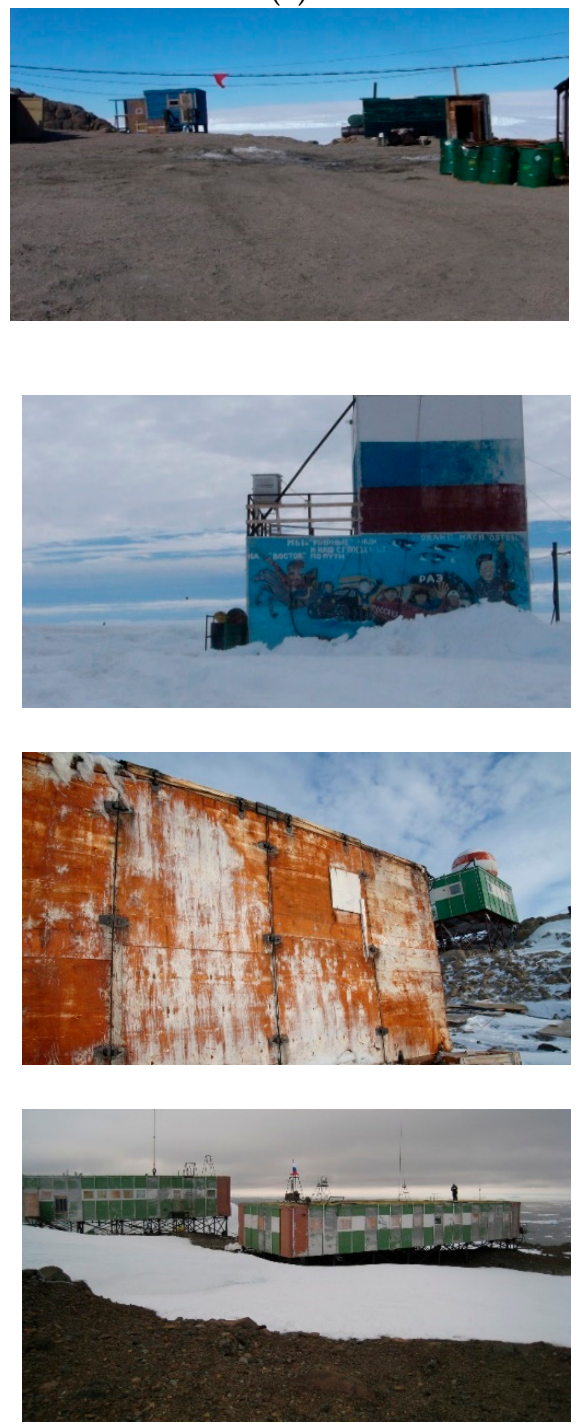

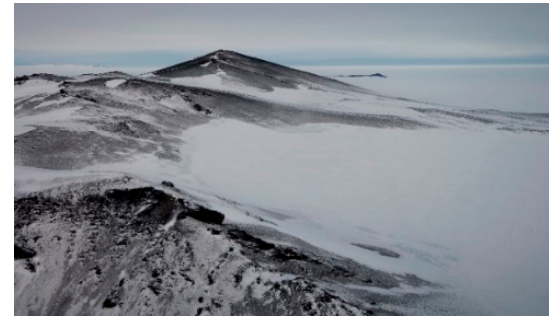

(b)

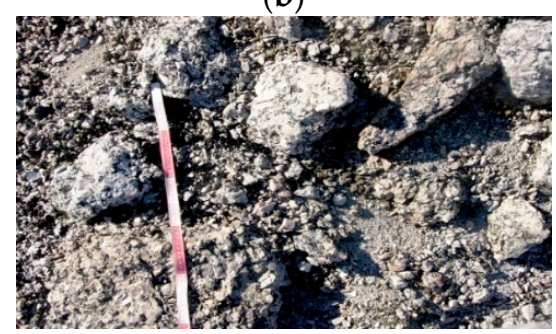

(c)

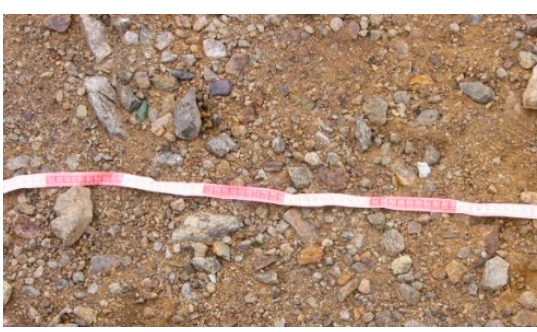

(d)

(e)
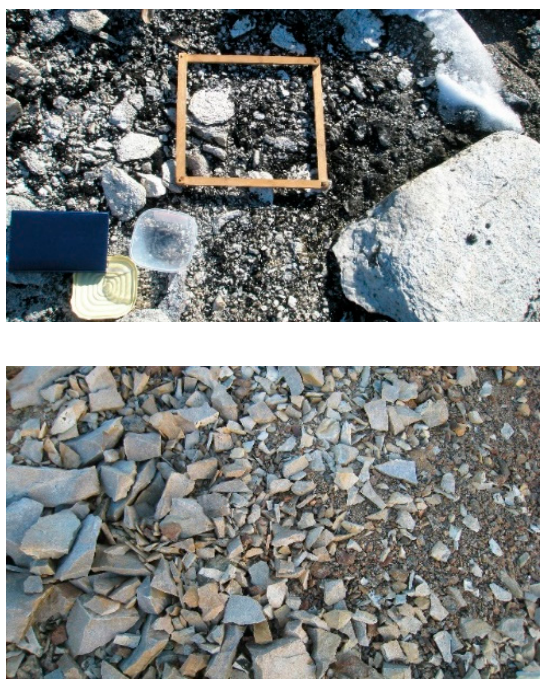

(f)

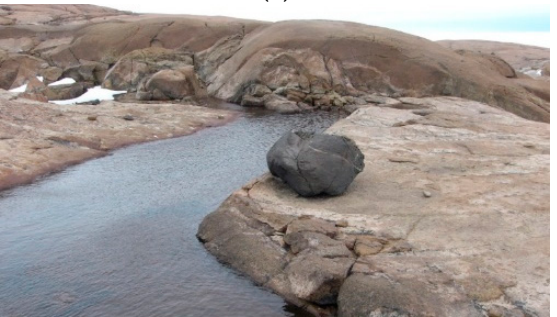

(g)

Figure 2. Anthropogenic and natural landscapes of the studied Antarctic stations and their vicinity: (a) Bellingshausen Station; (b) the Hudson Mountains; (c) Druzhnaya 4 Station; (d) Mirniy Station; (e) Leningradskaya Station; (f) Russkaya Station; (g) the Haswell Archipelago. 
Since benz[a]pyrene is the most well-studied polyarene with a well-developed regulatory framework regarding its concentration limits in various media, researchers often define concentrations of individual PAHs by analogy with the one of benz[a]pyrene.

The calculation of benz[a]pyrene equivalents (BaPYR-equivalents) is the product of the PAH concentration by its toxic equivalency factor (TEF); the values of these factors are published by Nisbet [35]. The possibility of calculating these factors for the Antarctica soils was explained in the work earlier [36].

Statistical treatment of the data was carried out with STATISTICA 10.0 software. Oneway ANOVA was applied in order to test the statistical significance of differences among obtained data. The essence of the method is based on the estimation of the significance of the average differences among three or more independent groups of data combined by one feature (factor). The null hypothesis of the average equality is tested during the analysis, suggesting the provisions on the equality or inequality of variances. In case of rejection of the null hypothesis, basic analysis is not applicable. If the variances are equal, the f-test Fisher criterion is used for evaluation of the intergroup and intergroup variability. If $f$ statistics exceed the critical value, the null hypothesis is rejected considering the inequality of averages. A post hoc test (Fisher's least significant difference) was used to provide detailed evaluation of average differences among analyzed groups of data. A feature of the post hoc test is the application of intra-group mean squares for the assessment of any pair averages. Differences were considered to be significant at the $95 \%$ confidence level. PAH concentrations were analysed at least in triplicate. Calculated mean concentrations were provided with standard deviations $(\bar{X} \pm S)$.

\section{Results and Discussion}

Data on the quantitative composition of PAHs are given in Figure 3. The data obtained indicate that Antarctica has a group of soils with a relatively low total PAH content (maximum-90 ng/g) and soils with a high content of PAHs (hundreds of $\mathrm{ng} / \mathrm{g}$ ).

Apparently, the total PAH content of approximately $30 \mathrm{ng} / \mathrm{g}$ should be recognized as normal for the Antarctic soils. Meanwhile, in the soils of conditional reference landscapes the content of benz(a)pyrene, which is a conditional marker of anthropogenic pollution, is very low or equals zero (Table 1). There are also soils with increased benz(a)pyrene concentration and cumulative PAH ratio- the ones around Mirniy and Druzhnaya 4 stations. PAHs accumulate there as a result of their light fraction, while the proportion of benz(a)pyrene is low. The following group of soils stands out-soil from Bellingshausen Station (a very intensely anthropogenically developed landscape) and imported agrosoils for growing flowers (from St. Petersburg). In any case, the agrosoils show enormous content of PAHs even in comparison with the most contaminated indigenous soils of the Antarctica. This indicated that the baseline or threshold concentrations for soils of the Antarctic should be completely different from those that exist in Russia or Germany. As for component composition, light PAHs undoubtedly dominate here, and the content of benz(a)pyrene is high. It is important to note that none of the studied natural soils of Antarctica (even the exposed ones) exceeded the maximum allowable concentration limits for benz(a)pyrene, while in the imported soils the share of this substance exceeds the existing standard significantly.

Statistical processing of analytical results enabled the detection of significant variations between the spectrum of PAHs in the soil of the reference landscape of Mount Moses, the imported soil at Russkaya Station $(p<0.02)$, and the imported soil at Leningradskaya Station $(p<0.03)$. The difference in the PAH content is observed as a statistical trend when comparing the soil of the reference landscape and the contaminated soil at Druzhnaya 4 Station $(p<0.08)$. There is no significant increase in PAHs in the soil near the airfield at Bellingshausen Station $(p<0.14)$ compared to the reference soil sample. 

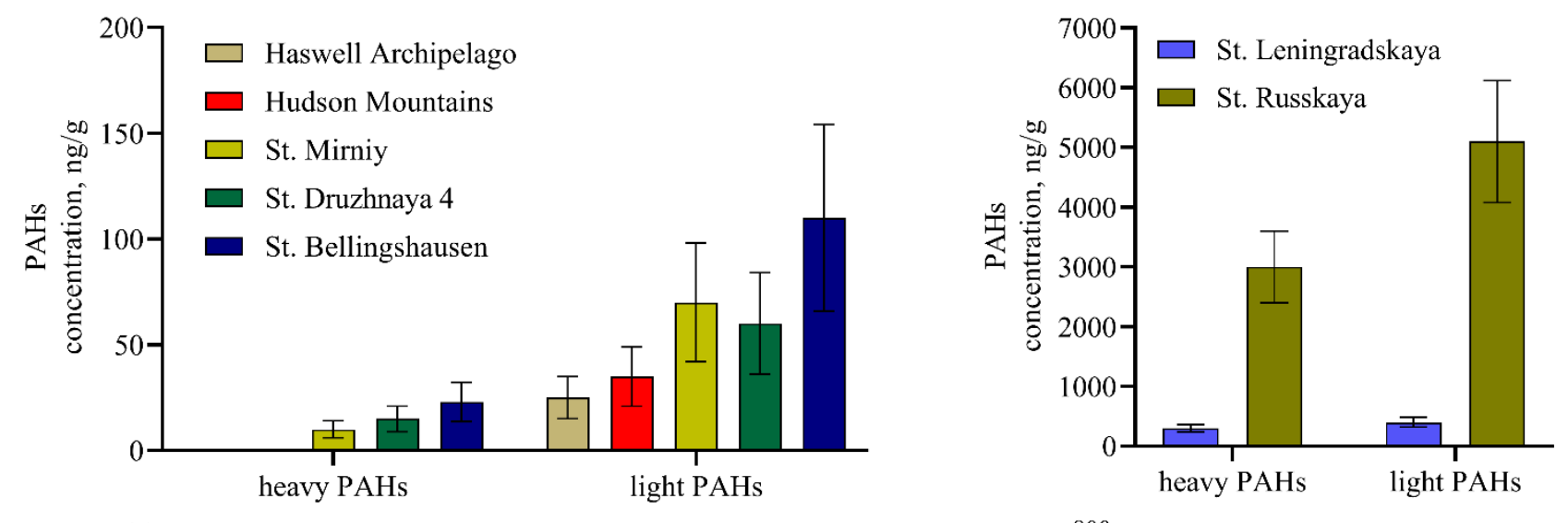

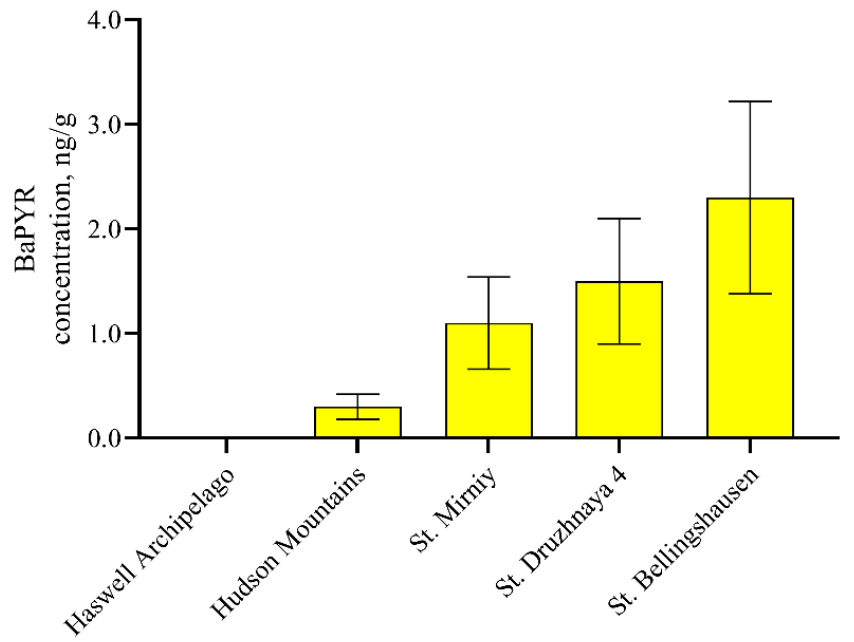

(a)

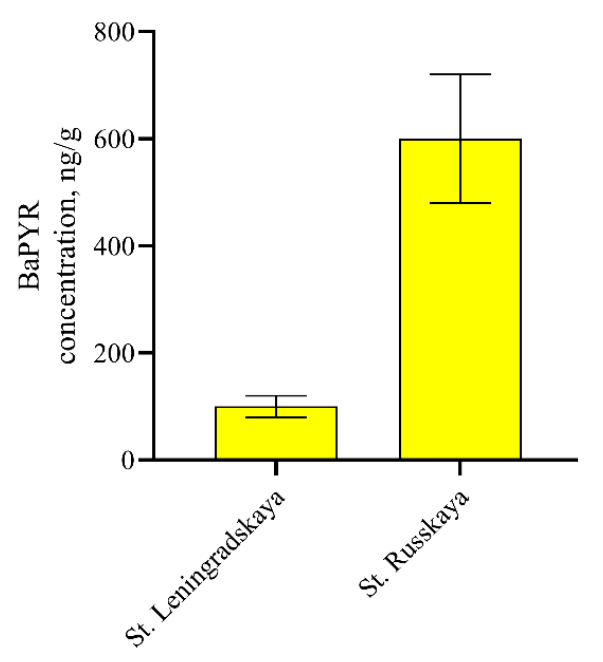

(b)

Figure 3. PAH fractions in Antarctica soils (a) and former agrosoils (b).

The obtained primary and original results of the studied content and fractional composition of PAHs indicate the initial-stage contamination of soils in landscapes that are exposed to intensive anthropogenic development. Soils that can be considered comparison objects or reference samples have also been identified. Imported soils are fundamentally different in the composition of PAHs, which is reflected in predominating anthropogenic components.

Despite the recorded low content of individual PAHs in undisturbed areas, the calculation of indicator (isomeric) ratios showed that both heavy and light PAHs in all samples under study are of pyrogenic genesis (Table 2). On the territory of the Antarctic stations and in imported soils at the Russkaya and Leningradskaya stations the origin is seen as pyrogenic. Calculation of the BaPYR/BghiPER ratio indicates the transport-induced origin of heavy polyarenes in imported soils at concentrations comparable with the St. Petersburg soils [37]. Thus, the requirement of the Madrid protocol, which prohibits the soil transportation to Antarctica, are correct and based on potential environmental damage and contamination risk for a pristine environment. Meanwhile, those substrata, which were transported legally, could be used for experimental work and the monitoring of PAHs fate in both cases-if the stations mentioned above will be renovated and whole-wintering again and in case of the continuation of their state as abandoned stations with fly in fly visiting. 
Table 1. Mass fraction of PAHs (ng/g) in Antarctica soils.

\begin{tabular}{|c|c|c|c|c|c|c|c|c|}
\hline $\begin{array}{l}\text { Subject of } \\
\text { Research }\end{array}$ & $\underset{\left(2^{2}\right)}{\text { NAPH }^{1}}$ & $\begin{array}{c}\text { FLU } \\
(3)\end{array}$ & $\underset{(3)}{\text { PHEN }}$ & $\underset{(3)}{\operatorname{ANTH}}$ & $\begin{array}{c}\text { FLUOR } \\
(4)\end{array}$ & $\underset{(4)}{\text { PYR }}$ & $\underset{(4)}{\mathrm{BaANTH}}$ & $\underset{(4)}{\text { CHRY }}$ \\
\hline \multicolumn{9}{|c|}{ Non-disturbed soils } \\
\hline Moses & $\mathrm{n} / \mathrm{d}^{3}$ & $\mathrm{n} / \mathrm{d}$ & $2.0 \pm 0.8$ & $14 \pm 6$ & $\mathrm{n} / \mathrm{d}$ & $4.0 \pm 1.6$ & $6.0 \pm 2.1$ & $0.30 \pm 0.12$ \\
\hline Maish & $13 \pm 5$ & $\mathrm{n} / \mathrm{d}$ & $1.8 \pm 0.7$ & $14 \pm 6$ & $\mathrm{n} / \mathrm{d}$ & $9 \pm 4$ & $\mathrm{n} / \mathrm{d}$ & $1.3 \pm 0.5$ \\
\hline Haswell & $\mathrm{n} / \mathrm{d}$ & $\mathrm{n} / \mathrm{d}$ & $2.2 \pm 0.9$ & $11 \pm 5$ & $1.6 \pm 0.6$ & $2.9 \pm 1.2$ & $2.6 \pm 0.9$ & $1.2 \pm 0.5$ \\
\hline \multicolumn{9}{|c|}{ Polluted soils } \\
\hline $\begin{array}{l}\text { Bellingshausen } \\
\text { near airport }\end{array}$ & $60 \pm 25$ & $\mathrm{n} / \mathrm{d}$ & $6.0 \pm 2.5$ & $70 \pm 14$ & $2.5 \pm 1.0$ & $3.9 \pm 1.6$ & $25 \pm 9$ & $3.1 \pm 1.3$ \\
\hline Druzhnaya 4 & $21 \pm 9$ & $\mathrm{n} / \mathrm{d}$ & $3.0 \pm 1.2$ & $28 \pm 6$ & $1.5 \pm 0.6$ & $13 \pm 5$ & $28 \pm 10$ & $3.0 \pm 1.3$ \\
\hline Mirniy & $19 \pm 8$ & $\mathrm{n} / \mathrm{d}$ & $4.5 \pm 1.8$ & $40 \pm 8$ & $1.3 \pm 0.5$ & $8 \pm 3$ & $8.0 \pm 2.8$ & $1.7 \pm 0.9$ \\
\hline \multicolumn{9}{|c|}{ Former agrosoils } \\
\hline Russkaya & $47 \pm 20$ & $30 \pm 10$ & $48 \pm 20$ & $700 \pm 140$ & $120 \pm 40$ & $1500 \pm 230$ & $1300 \pm 220$ & $700 \pm 170$ \\
\hline Leningradskaya & $\mathrm{n} / \mathrm{d}$ & $\mathrm{n} / \mathrm{d}$ & $4.6 \pm 1.8$ & $70 \pm 14$ & $10 \pm 4$ & $150 \pm 60$ & $120 \pm 26$ & $70 \pm 30$ \\
\hline $\begin{array}{l}\text { Subject of } \\
\text { Research }\end{array}$ & $\begin{array}{c}\text { BbFLUOR } \\
\text { (5) }\end{array}$ & $\underset{(5)}{\text { BkFLUOR }}$ & $\underset{(5)}{\text { BaPYR }}$ & $\underset{\text { (5) }}{\text { DBahANTH }}$ & $\underset{\text { (6) }}{\text { BghiPER }}$ & \multicolumn{2}{|c|}{$\begin{array}{c}\text { IPYR } \\
\text { (6) }\end{array}$} & $\sum \mathbf{P A H}$ \\
\hline \multicolumn{9}{|c|}{ Non-disturbed soils } \\
\hline Moses & $0.7 \pm 0.3$ & $\mathrm{n} / \mathrm{d}$ & $0.31 \pm 0.12$ & $0.60 \pm 0.24$ & $\mathrm{n} / \mathrm{d}$ & & & $28 \pm 11$ \\
\hline Maish & $\mathrm{n} / \mathrm{d}$ & $\mathrm{n} / \mathrm{d}$ & $0.42 \pm 0.16$ & $\mathrm{n} / \mathrm{d}$ & $\mathrm{n} / \mathrm{d}$ & & & $40 \pm 16$ \\
\hline Haswell & $1.3 \pm 0.5$ & $\mathrm{n} / \mathrm{d}$ & $0.34 \pm 0.14$ & $\mathrm{n} / \mathrm{d}$ & $\mathrm{n} / \mathrm{d}$ & & & $23 \pm 9$ \\
\hline \multicolumn{9}{|c|}{ Polluted soils } \\
\hline $\begin{array}{l}\text { Bellingshausen } \\
\text { near airport }\end{array}$ & $6.0 \pm 2.4$ & $\mathrm{n} / \mathrm{d}$ & $1.8 \pm 0.8$ & $3.0 \pm 1.2$ & $\mathrm{n} / \mathrm{d}$ & 7.0 & 2.6 & $190 \pm 40$ \\
\hline Druzhnaya 4 & $19 \pm 8$ & $10 \pm 4$ & $2.0 \pm 0.8$ & $4.3 \pm 1.7$ & $\mathrm{n} / \mathrm{d}$ & & & $141 \pm 28$ \\
\hline Mirniy & $5.0 \pm 2.0$ & $2.7 \pm 1.1$ & $1.0 \pm 0.4$ & $1.1 \pm 0.4$ & $\mathrm{n} / \mathrm{d}$ & & & $92 \pm 18$ \\
\hline \multicolumn{9}{|c|}{ Former agrosoils } \\
\hline Russkaya & $700 \pm 150$ & $800 \pm 160$ & $370 \pm 70$ & $600 \pm 150$ & $110 \pm 22$ & \multirow{2}{*}{\multicolumn{2}{|c|}{$\begin{array}{c}650 \pm 130 \\
65 \pm 24\end{array}$}} & $8100 \pm 1600$ \\
\hline Leningradskaya & $70 \pm 24$ & $80 \pm 30$ & $36 \pm 15$ & $100 \pm 25$ & $9 \pm 3$ & & & $820 \pm 160$ \\
\hline
\end{tabular}

Table 2. Values of indicator (isomeric) ratios and possible origin sources of polyarenes.

\begin{tabular}{|c|c|c|c|c|c|c|c|c|}
\hline \multirow{2}{*}{$\begin{array}{l}\text { Subject of } \\
\text { Research }\end{array}$} & \multicolumn{2}{|c|}{$\begin{array}{l}\text { PHEN/ } \\
\text { ANTH }\end{array}$} & \multicolumn{2}{|c|}{ ANTH/(ANTH + PHEN) } & \multicolumn{2}{|c|}{$\begin{array}{c}\text { BaANTH/ } \\
\text { (BaANTH + CHRY) }\end{array}$} & \multicolumn{2}{|c|}{$\begin{array}{l}\text { BaPYR/ } \\
\text { BghiPER }\end{array}$} \\
\hline & Value & Genesis & Value & Genesis & Value & Genesis & Value & Genesis \\
\hline \multicolumn{9}{|c|}{ Non-disturbed soils } \\
\hline Moses & 0.14 & Pyro $^{1}$ & 0.88 & Pyro & 0.95 & Pyro & $\mathrm{n} / \mathrm{d}$ & $\mathrm{n} / \mathrm{d}$ \\
\hline Maish & 0.13 & Pyro & 0.89 & Pyro & $\mathrm{n} / \mathrm{d}^{2}$ & $\mathrm{n} / \mathrm{d}$ & $\mathrm{n} / \mathrm{d}$ & $\mathrm{n} / \mathrm{d}$ \\
\hline Haswell & 0.20 & Pyro & 0.83 & Pyro & 0.68 & Pyro & $\mathrm{n} / \mathrm{d}$ & $\mathrm{n} / \mathrm{d}$ \\
\hline \multicolumn{9}{|c|}{ Polluted soils } \\
\hline $\begin{array}{l}\text { Bellingshausen } \\
\text { near airport }\end{array}$ & 0.09 & Pyro & 0.92 & Pyro & 0.89 & Pyro & $\mathrm{n} / \mathrm{d}$ & $\mathrm{n} / \mathrm{d}$ \\
\hline Druzhnaya 4 & 0.11 & Pyro & 0.90 & Pyro & 0.90 & Pyro & $\mathrm{n} / \mathrm{d}$ & $\mathrm{n} / \mathrm{d}$ \\
\hline Mirniy & 0.11 & Pyro & 0.90 & Pyro & 0.82 & Pyro & $\mathrm{n} / \mathrm{d}$ & $\mathrm{n} / \mathrm{d}$ \\
\hline \multicolumn{9}{|c|}{ Former Agrosoils } \\
\hline Russkaya & 0.07 & Pyro & 0.94 & Pyro & 0.65 & Pyro & 3.36 & Trans $^{3}$ \\
\hline Leningradskaya & 0.07 & Pyro & 0.94 & Pyro & 0.63 & Pyro & 4.00 & Trans \\
\hline
\end{tabular}

${ }^{1}$ Pyrogenic; ${ }^{2}$ no data; ${ }^{3}$ Transport.

The sum of the studied PAHs in BaPYR equivalents (Figure 4) exceeds the rates of benz[a]pyrene (maximum permissible concentration (MPC) - $20 \mathrm{ng} / \mathrm{g}$ [38]) allowed in the Russian Federation in soils from the Bellingshausen and Druzhnaya 4 stations, as well as in imported argosoils at the Russkaya and Leningradskaya stations. The highest concentration of PAHs in BaPYR equivalents was recorded in former transported agrosoils 
( 3731.84 and $571.15 \mathrm{ng} / \mathrm{g}$ ). In this case, there is an obvious excess of the current PAHs concentrations in the Urbic soils of St. Petersburg [37].

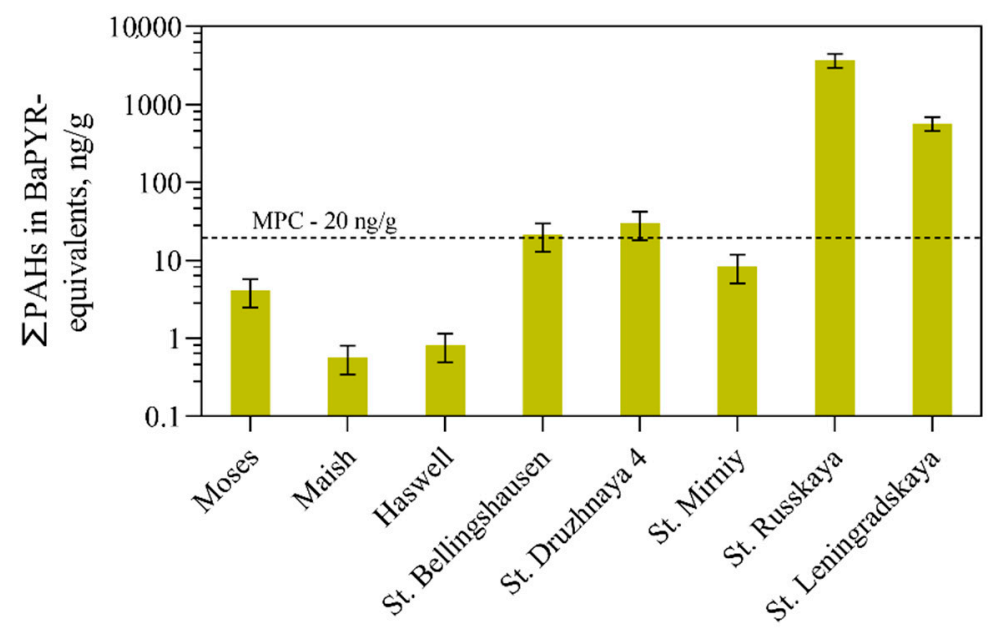

Figure 4. BaPYR-equivalents $\sum \mathrm{PAH}$.

According to some other researchers, the soil cover around Antarctic stations may be strongly contaminated with polyarenes. For example, in a $3.5 \mathrm{~cm}$ layer of soil around the Ferraz station, Martins [8] presents data about the content of the sum of high molecular weight PAHs (4-6 rings) equal to $454.9 \mathrm{ng} / \mathrm{g}$. Also based on the calculations of isomer ratios, the authors identified a pyrogenic source of these polyarenes. At the same time, the content of these compounds is significantly lower (from 11.8 to $270.5 \mathrm{ng} / \mathrm{g}$ ) in nonanthropogenic affected areas of Admiralty Bay [8,39]. Aislabie published shocking data, where at Scott's Base they found $\sum_{15}$ PAHs concentrations of $8105 \mathrm{ng} / \mathrm{g}$ near the old drum storage. Although in background soils around Scott's Base (McMurdo Dry Valley) the sum of PAHs is $15-45 \mathrm{ng} / \mathrm{g}$ [40]. At the opposite end of the globe, also in the polar environment (Ny-Ålesund, Svalbard, Arctic) Wang and colleagues found PAH sum content in soils from 36.9 to $323 \mathrm{ng} / \mathrm{g}$ [41]. Comparing our data with literature sources, we can see that the background content of polyarenes is comparable with the results of other researchers in both the Antarctic and Arctic regions. However, many authors provides data on extremely high PAH content in anthropogenic-loaded areas, which are comparable with our results for the Leningradskaya and Russkaya stations.

In this study, we used the HPLC method for the identification of PAHs, which method is effective for the detection the biogenic and anthropogenic PAHs in soils. Its effectiveness has been approved both for mineral soils $[17,29,42]$ and for peat sediments [30]. However, some (mainly highly contaminated) samples of environmental compounds also contain large concentrations of other polyarenes (alkyl-substituted, hydroxyl-derivatives, etc.) in excess of the 16 priority PAHs. In these cases, usage of the HPLC method causes problems due to identification errors of the detected components. Their quantification can also be difficult as a result of overlapping or incomplete separation of the chromatographic peaks. One way to solve this problem is to use a detector with a diode matrix that gives the possibility of identifying compounds by their ultraviolet spectra. However, the issues of valid and high-quality quantification of PAHs in such complex and highly contaminated samples remain open.

\section{Conclusions}

Data on PAHs distribution in Antarctic soils showed that former agrosoils, transported from St. Petersburg to Antarctica contain the PAHs fractions in a stable state during two decades after polar stations abandoning. The content of PAHs is numerously higher in transported agrosoils than in both contaminated and pristine soils of Antarctica. Obviously, the climatic conditions of the Antarctic region do not stimulate the processes of biological 
and physico-chemical decomposition of contaminants. This fact shows the absolute necessity to implement international agreements (Protocol on Environmental Protection to the Antarctic Treaty, Madrid, 1991) on the prevention of anthropogenic impacts on Antarctic ecosystems. The pool of polyarenes in the studied local Antarctic soils is represented mainly by light PAHs - naphthalene, phenanthrene, fluoranthene, pyrene, etc. Pollution changes the composition of PAHs in soils-a quantitative accumulation of both light and heavy PAHs is accompanied by a qualitative increase in the proportion of heavy polyarenes. The content of benz(a)pyrene does not exceed the maximum allowable concentration (adopted in the Russian Federation) [38]. However, the calculation of BaPYR equivalents showed that the sum of the studied PAHs exceeds the limits in the soils of the Bellingshausen and Druzhnaya 4 stations and in the former transported agrosoils at the Russkaya and Leningradskaya stations. The primary empiric and statistical analysis of the data showed that the pollution of Antarctic soils with heavy PAHs is at the very initial stage, as there is no stable or statistically significant accumulation of PAHs in the soils of both maritime and continental Antarctica. However, while the concentrations of individual polyarenes are at a low, the calculation of indicator ratios showed that the genesis of PAHs, even in anthropogenically undisturbed territories, is pyrogenic. The transportation of soils to Antarctica, which was occasional in Soviet times before the implementation of the Madrid protocol, resulted in the fact that we have two soils which existed in two of the most remoted stations for 20 years. These soils do not show any features of self-remediation and stay intensively contaminated with polyarenes. A decision to ban the transport of soil and ground to Antarctica is certainly the right one. This rule should not be ignored now and in the future, because it will ensure the sustainability of the Earth's pristine ecosystem and provide a benchmark for future research.

Author Contributions: Conceptualization, E.L. and E.A.; methodology, E.L. and E.A; software, T.N.; validation, E.L. and E.A.; formal analysis, E.L., E.A. and T.N.; investigation, E.L. and E.A; resources, E.L. and E.A.; data curation, E.L. and E.A.; writing-original draft preparation, E.A. and T.N.; writing — review and editing, E.L.; visualization, E.A. and T.N.; supervision, E.L.; project administration, E.A.; funding acquisition, E.L. and E.A. All authors have read and agreed to the published version of the manuscript.

Funding: The reported study was funded by the Federal budget (no. AAAA-A17-117122290011-5) and RFBR grant (No. 19-05-50107).

Data Availability Statement: Not applicable.

Acknowledgments: We are grateful to the developers of the Quantarctica project (Norwegian Polar Institute) for providing GIS data.

Conflicts of Interest: The authors declare no conflict of interest. The funders had no role in the design of the study; in the collection, analyses, or interpretation of data; in the writing of the manuscript; or in the decision to publish the results.

\section{References}

1. Waterhouse, E.J. (Ed.) Ross Sea Region 2001: A State of the Environment Report for the Ross Sea Region of Antarctica, 1st ed.; New Zealand Antarctic Institute: Christchurch, New Zealand, 2001.

2. United Nations. Protocol on Environmental Protection to the Antarctic Treaty. 1991. Available online: https://treaties.un.org/ Pages/showDetails.aspx?objid=080000028006ab63\&clang=_en (accessed on 26 August 2021).

3. Bargagli, R. Environmental contamination in Antarctic ecosystems. Sci. Total Environ. 2008, 400, 212-226. [CrossRef] [PubMed]

4. Ji, X.; Abakumov, E.; Polyakov, V.; Xie, X.; Dongyang, W. The ecological impact of mineral exploitation in the Russian Arctic: A field-scale study of polycyclic aromatic hydrocarbons (PAHs) in permafrost-affected soils and lichens of the Yamal-Nenets autonomous region. Environ. Pollut. 2019, 255, 113239. [CrossRef] [PubMed]

5. Ji, X.; Abakumov, E.; Polyakov, V. Assessments of pollution status and human health risk of heavy metals in permafrost-affected soils and lichens: A case-study in Yamal Peninsula, Russia Arctic. Hum. Ecol. Risk Assess. 2019, 25, 2142-2159. [CrossRef]

6. Ji, X.; Abakumov, E.; Xie, X. Atmosphere-ocean exchange of heavy metals and polycyclic aromatic hydrocarbons in the Russian Arctic Ocean. Atmos. Chem. Phys. 2019, 19, 13789-13807. [CrossRef]

7. AMAP. Arctic Pollution Issues: A State of the Arctic Environment Report. Arctic Monitoring and Assessment Programme (AMAP); AMAP: Oslo, Norway, 1997; 188p. 
8. Martins, C.C.; Bicego, M.C.; Rose, N.L.; Taniguchi, S.; Lourenco, R.A.; Figueira, R.C.L.; Mahiques, M.M.; Montone, R.C. Historical record of polycyclic aromatic hydrocarbons (PAHs) and spheroidal carbonaceous particles (SCPs) in marine sediment cores from Admiralty Bay, King George Island, Antarctica. Environ. Pollut. 2010, 158, 192-200. [CrossRef] [PubMed]

9. Grondahl, F.; Sidenmark, J.; Thomsen, A. Survey of waste water disposal practices at Antarctic research stations. Polar Res. 2008, 28, 298-306. [CrossRef]

10. Montone, R.C.; Martins, C.C.; Bicego, M.C.; Taniguchi, S.; Silva, D.A.M.; Campos, L.S.; Weber, R.R. Distribution of sewage input in marine sediments around a maritime Antarctic research station indicated by molecular geochemical indicators. Sci. Total Environ. 2010, 408, 4665-4671. [CrossRef]

11. IARC. IARC Monographs on the Evaluation of the Carcinogenic Risk of Chemicals to Humans. Polynuclear Aromatic Compounds, Part 1, Chemical, Environmental and Experimental Data, 1st ed.; International Agency for Research on Cancer: Lyon, France, 1983; 477p.

12. U.S. Environmental Protection Agency. Method 3550b: Ultrasonic Extraction; Office of Health and Environmental Assessment: Washington, DC, USA, 1996; Revision 2.

13. U.S. Environmental Protection Agency. Method 3630c: Silica Gel Cleanup; Office of Health and Environmental Assessment: Washington, DC, USA, 1996; Revision 3.

14. U.S. Environmental Protection Agency. Method 8310: Polynuclear Aromatic Hydrocarbons; Office of Health and Environmental Assessment: Washington, DC, USA, 1996; Revision 0.

15. U.S. Environmental Protection Agency. Evaluation and Estimation of Potential Carcinogenic Risks of Polynuclear Aromatic Hydrocarbons: Carcinogen Assessment Group; Office of Health and Environmental Assessment: Washington, DC, USA, 1985.

16. Bouloubassi, I.; Saliot, A. Investigation of anthropogenic and natural organic inputs in estuarine sediments using hydrocarbon markers (NAH, LAB, PAH). Oceanol. Acta 1993, 1, 145-161.

17. Gennadiev, A.N.; Pikovsky, Y.I.; Florovskaya, V.N.; Alekseeva, T.A.; Kozin, I.S.; Ogloblina, A.I.; Ramenskaya, M.E.; Teplitskaya, T.A.; Shurubor, E.I. Geochemistry of Polycyclic Aromatic Hydrocarbons in Rocks and Soils, 1st ed.; Gennadiev, A.N., Pikovsky, Y.I., Eds.; Moscow University Publ.: Moscow, Russia, 1996; 192p.

18. Na, G.; Gao, Y.; Li, R.; Gao, H.; Hou, C.; Ye, J.; Jin, S.; Zhang, Z. Occurrence and Sources of Polycyclic Aromatic Hydrocarbons in Atmosphere and Soil from 2013 to 2019 in the Fildes Peninsula, Antarctica. Mar. Pollut. Bull. 2020, 156, 111173. [CrossRef] [PubMed]

19. Yunker, M.B.; Macdonald, R.W. Alkane and PAH depositional history, sources and fluxes in sediments from Fraser River basin and Strait of Georgia, Canada. Org. Geochem. 2004, 34, 1429-1454. [CrossRef]

20. Pelletier, E.; Delille, D.; Delille, B. Crude oil bioremediation in sub-Antarctic intertidal sediments: Chemistry and toxicity of oiled residues. Mar. Environ. Res. 2004, 57, 311-327. [CrossRef] [PubMed]

21. UNEP (United Nations Environment Programme Chemicals). Regionally Based Assessment of Persistent Toxic Substances. Antarctic Regional Report, 1st ed.; Global Environment Facility: Geneva, Switzerland, 2002.

22. Young, L.Y.; Cerniglia, C.E. Microbial Transformation and Degradation of Toxic Organic Chemicals, 1st ed.; Wiley-Liss, Inc.: New York, NY, USA, 1995; 654p.

23. Abakumov, E.V. The sources and composition of humus in some soils of west Antarctica. Eurasian Soil Sci. 2010, 5, 499-508. [CrossRef]

24. Coulon, F.; Pelletier, E.; Gourhant, L.; Delille, D. Effects of nutrient and temperature on degradation of petroleum hydrocarbons in contaminated sub-Antarctic soil. Chemosphere 2005, 58, 1439-1448. [CrossRef] [PubMed]

25. Abakumov, E.; Lupachev, A.; Andreev, M.; Wang, W.; Ji, X. The influence of brown and south polar skua on the content of plant nutrient in the soils from the Fildes Peninsula (King George Island, West Antarctica). Chem. Ecol. 2021, 37, 185-199. [CrossRef]

26. Lupachev, A.V.; Abakumov, E.V.; Goryachkin, S.V.; Veremeeva, A.A. Soil cover of the Fildes Peninsula (King George Island, West Antarctica). Catena 2020, 193, 104613. [CrossRef]

27. Lupachev, A.V.; Gubin, S.V.; Abakumov, E.V. Levels of biogenic-abiogenic interaction and structural organization of soils and soil-like bodies in Antarctica. Lect. Notes Earth Sys. Sci. 2020, 481-500. [CrossRef]

28. PND F 16.1:2:2.2:3.62-09; Quantitative Chemical Analysis of Soils. Technique for Measuring the Mass Fraction of Polycyclic Aromatic Hydrocarbons in Soils, Bottom Sediments, Sewage Sludge and Industrial Waste by High Performance Liquid Chromatography, 1st ed.; FGA Federal Center for Analysis and Assessment of Technogenic Impact: Moscow, Russia, 2009; 23p. (In Russian)

29. Gabov, D.N.; Beznosikov, V.A.; Kondrateno, B.M. Polycyclic aromatic hydrocarbons in background podzolic and gleyic peatpodzolic soils. Eurasian Soil Sci. 2007, 40, 256-264. [CrossRef]

30. Gabov, D.N.; Beznosikov, V.A.; Kondratenok, B.M.; Yakovleva, E.V. Formation of polycyclic aromatic hydrocarbons in northern and middle taiga soils. Eurasian Soil Sci. 2008, 41, 1180-1188. [CrossRef]

31. Budzinski, H.; Jones, I.; Bellocq, J.; Pierard, C.; Garrigues, P. Evaluation of sediment contamination by polycyclic aromatic hydrocarbons in the Gironde estuary. Mar. Chem. 1997, 58, 85-97. [CrossRef]

32. Yunker, M.B.; Macdonald, R.W.; Vingarzan, R.; Mitchell, R.H.; Goyette, D.; Sylvestre, S. PAHs in the Fraser River basin: A critical appraisal of PAH ratios as indicators of PAH source and composition. Org. Geochem. 2002, 33, 489-515. [CrossRef]

33. Tobiszewski, M.; Namiesnik, J. PAH diagnostic ratios for the identification of pollution emission sources. Environ. Pollut. 2012, 162, 110-119. [CrossRef] [PubMed]

34. Pandey, P.K.; Patel, K.S.; Lenicek, J. Polycyclic aromatic hydrocarbons: Need for assessment of health risks in India? Study of an urban-industrial location in India. Environ. Monit. Assess. 1999, 59, 287-319. [CrossRef] 
35. Nisbet, I.C.T.; Lagoy, P.K. Toxic equivalency factors (TEFs) for polycyclic aromatic hydrocarbons (PAHs). Regul. Toxicol. Pharmacol. 1992, 16, 290-300. [CrossRef]

36. Abakumov, E.; Nizamutdinov, T.; Yaneva, R.; Zhiyanski, M. Polycyclic aromatic hydrocarbons and potentially toxic elements in soils of the vicinity of the Bulgarian Antarctic station St. Kliment Ohridski (Antarctic Peninsula). Front. Environ. Sci. 2021, 9 , 656271. [CrossRef]

37. Shamilishvili, G.; Abakumov, E. Organic and inorganic contaminants in urban soils of St. Petersburg (Russia). In Proceedings of the International Congress on Soils of Urban, Industrial, Traffic, Mining and Military Areas, Moscow, Russia, 21-26 May 2017; Springer: Cham, Switzerland, 2019. [CrossRef]

38. GN 2.1.7.2041-06; Hygienic Standards. Maximum Permissible Concentration (MPC) of Chemical Substances in the Soil, 1st ed.; Federal Center for Hygiene and Epidemiology of Rospotrebnadzor: Moscow, Russia, 2006; 15p. (In Russian)

39. Martins, C.C.; Bícego, M.C.; Taniguchi, S.; Montone, R.C. Aliphatic and Polycyclic Aromatic Hydrocarbons in Surface Sediments in Admiralty Bay, King George Island, Antarctica. Antartic Sci. 2004, 16, 117-122. [CrossRef]

40. Aislabie, J.; Balks, M.; Astori, N.; Stevenson, G.; Symons, R. Polycyclic Aromatic Hydrocarbons in Fuel-Oil Contaminated Soils, Antarctica. Chemosphere 2004, 39, 2201-2207. [CrossRef]

41. Wang, Z.; Ma, X.; Na, G.; Lin, Z.; Ding, Q.; Yao, Z. Correlations between Physicochemical Properties of PAHs and Their Distribution in Soil, Moss and Reindeer Dung at Ny-Ålesund of the Arctic. Environ. Pollut. 2009, 157, 3132-3136. [CrossRef]

42. Lodygin, E.D.; Beznosikov, V.A.; Gabov, D.N.; Chukov, S.N. Polycyclic aromatic hydrocarbons in soils of Vasilievsky Island (St. Petersburg). Eurasian Soil Sci. 2008, 41, 1321-1326. [CrossRef] 